\title{
Rancang Bangun Aplikasi Pemetaan Digital Pada Universitas Muhammadiyah Riau
}

\author{
Royan Choiro Yahya ${ }^{1}$, Harun Mukhtar ${ }^{2 *}$, Regiolina Hayami ${ }^{3}$, Mitra Unik ${ }^{4}$ \\ ${ }^{123}$ Fakultas Ilmu Komputer Universitas Muhammadiyah Riau \\ email : ${ }^{1}$ royanchoiro@yahoo.com 2*harunmukhtar@umri.ac.id \\ 3regiolinahayami@umri.ac.id ${ }^{4}$ mitraunik@umri.ac.id
}

\begin{abstract}
The campus area is a place for students and teaching staff to carry out their routine activities. But there are times when campus visitors are not only focused on teaching staff or students who already know the ins and outs of the campus area. Some parties such as students' parents, new students, guests sometimes need a certain guide to find specific areas of interest in the campus area. The development of this application is carried out aiming to assist and alleviate these parties to search and find related areas. The design of the software is made with Adobe Edge Animation CC with Action Script 3.0. based on the results of this study it can be concluded that the Digital Mapping Application on the Muhammadiyah Riau Campus can overcome the problem of confusion among the parties when visiting the Muhammadiyah Riau campus.
\end{abstract}

Keywords: Adobe Edge Animation, Action script 3.0, Search engines, Digital mapping.

\begin{abstract}
Abstrak
Area kampus adalah tempat bagi mahasiswa dan staff pengajar untuk melaksanakan kegiatan rutin masing-masing. Namun ada kalanya pengunjung kampus tidak hanya terpaku pada staff pengajar atau pun mahasiswa yang sudah mengetahui seluk - beluk area kampus. Beberapa pihak seperti orang tua mahasiswa, mahasiswa baru, tamu terkadang membutuhkan panduan tertentu untuk mencari area tertenu yang dituju pada area kampus. Pembangunan aplikasi ini dilakukan bertujuan untuk membantu dan meringankan pihak-pihak tersebut untuk mencari dan menemukan area terkait. Perancangan perangkat lunak dibuat dengan Adobe Edge Animation CC dengan Action Script 3.0. berdasarkan hasil penelitian ini dapat disimpulkan bahwa Aplikasi Pemetaan Digital PadaKampus Muhammadiyah Riau dapat mengatasi masalah kebingungan para pihak - pihak tersebut ketika mengunjungi kampus Muhammadiyah Riau.
\end{abstract}

Kata Kunci: Adobe Edge Animation, Action script 3.0, Mesin pencari, Pemetaan digital.

\section{Pendahuluan}

Ilmu pengetahuan dan teknologi saat ini berkembang begitu pesat, khususnya teknologi informasi. Kebutuhan manusia akan segala sesuatu dituntut untuk lebih efisien, contohnya sangat jelas terasa dari perkembangan teknologi informasi tersebut, pekerjaan yang semula masih banyak menggunakan sistem manual pada saat ini sudah mulai berkurang, karena mulai beralih ke sistem yang sudah terkomputerisasi. Karena dengan proses yang sudah terkomputerisasi pekerjaan apapun akan lebih mudah dilakukan.
Universitas Muhammadiyah Riau merupakan salah satu instansi kampus umum yang memakai strategi perbaikan sistem untuk bisa bersaing. Sistem informasi ruangan dan Sistem Informasi fasilitas mencakup hal-hal yang terkait dengan proses yang ada di kampus ini. Ditambah lagi dengan dibangunnya Kompleks Kampus Muhammadiyah 2 Riau yang sedang dibangun, penulis merasa urgensi untuk mematangkan sistem informasi yang terdapat pada gedung dan ruangan Kampus. Aplikasi multimedia memungkinkan pemakai komputer untuk memperoleh output dalam bentuk yang lebih menarik dan interaktif 
dibandingkan dengan media elektronik lain. Dengan kompleksitas informasi yang ada, penulis merasa media yang ada sekarang tidaklah mencukupi untuk menghasilkan informasi yang memadai.

Seiring dengan berkembangnya gedung dan fasilitas Kampus Universitas Muhammadiyah RIAU dan bahkan dengan tambahan Kampus yang sedang dibangun, Penulis merasa urgensi dalam pembangunan aplikasi sistem informasi Peta Digital Pada Kampus Universitas Muhammadiyah Riau adalah yang harus dikerjakan dengan segera. Penulis sebagai salah anak didik dari Kampus Muhammadiyah Riau merasa ingin berkontribusi secara maksimal dan sesuai kemampuan penulis, dengan membangun aplikasi Peta Digital pada kampus Universitas Muhammadiyah Riau.

\section{Tinjauan Pustaka}

\subsection{Aplikasi}

Aplikasi adalah seperangkat intruksi khusus dalam komputer yang dirancang agar kita dapat menyelesaikan tugas-tugas tertentu.

\subsection{User Interface dan User Experience} (UI/UX)

User interface adalah bagaimana membangun aplikasi dengan kesan, penyajian dan interaktifitas sebuah produk atau aplikasi. User interface berfokus kepada tampilan sebuah produk atau aplikasi sedangkan user experience adalah bagaimana membangun kepuasan, kenyamanan dan loyalitas user atau pelanggan dengan cara meningkatkan kegunaan, kemudahan dan kenyamanan dalam menggunakan produk atau aplikasi.

\subsection{Informasi}

Informasi adalah data yang diolah menjadi bentuk yang lebih berguna dan yang lebih berarti bagi yang menerimanya dan bermanfaat dalam pengambilan keputusan saat ini aau mendatang

Sumber dari informasi adalah data. Data adalah kenyataan yang menggambarkan suatu kejadian yang nyata. Kejadian-kejadian adalah sesuatu yang terjadi pada saat yang tertentu.

\subsection{Kualitas Informasi}

Kualitas dari informasi tergantung dari 3 hal:

a. Informasi Harus Akurat Yang berarti informasi harus bebas dari kesalahankesalahan. Akurat juga berarti informasi harus jelas mencerminkan maksudnya. Informasi harus akurat karena dari sumber informasi sampai ke penerim informasi kemungkinan mengalami banyak gangguan yang dapat merubah atau merusak informasi tersebut.

b. Tepat Waktu Berarti informasi yang disampaikan kepada penerima tidak boleh memilik faktor keterlambatan. Informasi yang sudah usang tidak memiliki nilai lagi, karena informasi merupakan landasan di dalam pengambilan keputusan. Bila pengambilan keputusan terlambat, maka akan berakibat fatal untuk organisasi. Dewasa ini mahalnya nilai informasi disebabkan harus cepatnya informasi didapat, sehingga diperlukan teknologi mutakhir untuk mendapatkannya, mengolah dan mengirimkannya.

c. Relevan Berarti informasi tersebut memiliki manfaat untuk pemakainya. Nilai Informasi Nilai dari informasi dientukan oleh dua hal, yaitu manfaat dan biaya mendapatkannya. Suatu informasi dikatakan bernilai bila manfaatnya lebih efektif dibandingkan dengan biaya mendapatkannya. (PahrulRozi, 2012)

\subsection{Multimedia}

Multimedia adalah pemanfaatan komputer untuk membuat dan menggabungkan teks, grafik, audio, gambar bergerak (video dan animasi) dengan menggabungkan link dan tool 5 yang memungkinkan pemakai melakukan navigasi, berinteraksi, berkreasi dan berkomunikasi. Jika dipersempit dengan pengertian multimedia komputer maka multimedia diartikan sebagai sarana atau piranti komunikasi melalui lebih dari satu media komunikasi yang berbasis komputer untuk menyampaikan informasi. Dalam pengertian ini ada empat komponen penting multimedia. Pertama, harus ada komponen yang mengkoordinasikan apa yang dilihat dan didengar, berinteraksi dengan pengguna atau user. (Wahyu Tri Handono, 2012)

\subsubsection{Komponen Multimedia}

a. Teks

Teks adalah bentuk data multimedia yang paling mudah disimpan dan di kendalikan dan yang paling banyak kita lihat. Teks dapat berupa kata atau narasi dalam multimedia yang dapat menyajikan bahasa kita. Kebutuhan teks bergantung pada kegunaan aplikasi multimedia1. Misal sebuah game membutuhkan teks yang lebih sedikit. 
Sedangkan ensiklopedi membutuhkan teks yang lebih banyak. Contoh teks seperti: teks cetak, teks hasil scan, teks elektronik.

\section{b. Suara}

Penyampain sebuah informasi yang disertai desain grafis dan teks yang menarik, akan terasa hampa dan kurang menarik tanpa adanya suatu narasi atau sound yang menyertai dan menjelaskan informasi yang disampaikan. Contoh sound seperti : waveformaudio, MIDI soundtrack, compact disk video, MP3 file.

\section{c. Grafik}

Grafik menjadi nilai dan unsure tambahan suatu penyajian data (informasi). Alasan untuk menggunakan gambar dalam persentasi multimedia adalah karena menjadi lebih baik menarik perhatian dan dapat mengurangi kebosanan disbanding dengan teks. Sering dikatakan bahwa sebuah gambar dapat menggungkapkan seribu kata. Tapi itu hanya berlaku ketika kita bisa menampilkan ganbar yang diinginkan saat kita memerlukannya. Contoh grafik seperti : gambar vector, gambar bitmap, digitized picture, hyperpicture. (Tri EkoAddiAstari, 2013)

\section{d. Animasi}

Animasi berasal dari kata dalam Bahasa Inggris yaitu animate yang artinya menghidupkan, memberi jiwa dan mengerakan benda mati. Animasi merupakan proses membuat objek yang asalnya suatu benda mati, kemudian secara berurutan disusun dalam posisi yang berbeda seolah menjadi hidup.

\subsubsection{Multimedia BerbasisKomputer}

Saat ini teknologi komputer tidak hanya digunakan sebagai sarana komputasi pengolahan kata (word processor), tetapi juga sebagai sarana belajar multimedia yang memungkinkan mahasiswa membuat desain dan rekayasa suatu konsep dan ilmu pengetahuan. Sajian multimedia berbasis komputer dapat diartikan sebagai teknologi yang mengoptimalkan peran komputer sebagai sarana untuk menampilkan dan merekayasa teks, grafik, dan dalam sebuah tampilan yang terintegrasi

\subsection{Flash}

Flash merupakan salah satu teknologi komputasi multimedia. Multimedia diartikan sebagai kombinasi dari teks, grafik, animasi suara dan video yang digabung menjadi satu kesatuan kerja yang menghasilkan suatu informasi yang memiliki nilai komunikasi interaktif yang sangat tinggi bukan hanya dilihat sebagai hasil cetakan melainkan dapat didengar, membentuk simulasi dan animasi yang memiliki seni grafis yang sangat tinggi dalam penyampaiannya.

\subsection{Metode Pengerjaan}

Penelitian dilakukan langsung dilapangan, rumusan masalah juga ditemukan di lapangan, juga memungkinkan berubahubah sesuai data yang ada sehingga akan ditemukan sebuah teori baru di tengah lapangan. Penelitian ini bertolak dari cara berfikir deduktif. Penelitian ini akan menjabarkan kondisi konkrit dari obyek penelitian, menghubungkan suatu variabel atau kondisi dengan variabel atau kondisi lainnya dan selanjutnya akan dihasilkan deskripsi tentang obyek penelitian.

Maka dari itu disini penulis menggunakan 2 jenis metode untuk pembangunan dan pengembangan lebih lanjut aplikasi Aplikasi Pemetaan Digital Pada Universitas Muhammadiyah Riau yaitu dengan menggunakan Metode Waterfall dan Metode Prototype

\subsection{KerangkaPemikiran}

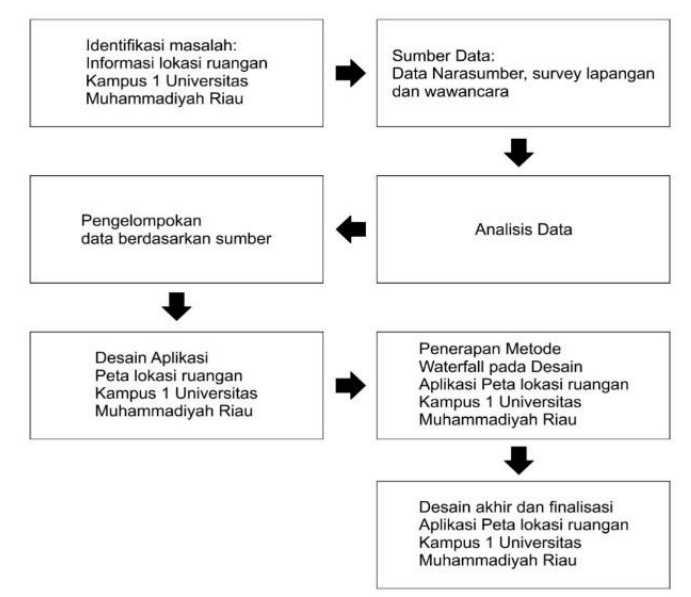

Gambar 1. Kerangka pemikiran penelitian

\subsection{BahanPenelitian}

Data yang dibutuhkan dalam menyelesaikan penelitian ini adalah hasil survey lapangan yang terdiri dari:

1. Data hasil survey lapangan berupa peta lokasi ruangan pada kampus 1 Universitas Muhammadiyah Riau.

Keterangan hasil wawancara dari narasumber berupa deskripsi dan fungsi masing-masing ruangan. 


\section{3}

\section{MetodeWaterfall}

Untuk

Pembangunan Aplikasi Multimedia

Metode penelitian yang diterapkan pada penelitian ini adalah dengan pengembangan metode waterfall. Metode waterfall merupakan model pengembangan system informasi yang sistematik dan sekuensial. Metode Waterfall memiliki tahapan-tahapan sebagai berikut:

\subsubsection{Requirement Analysis and Definition}

Layanan sistem, kendala, dan tujuan ditetapkan oleh hasil konsultasi dengan pengguna yang kemudian didefinisikan secara rinci dan berfungsi sebagai spesifikasi sistem.

\subsubsection{System and Software Design}

Tahapan perancangan sistem mengalokasikan kebutuhan-kebutuhan sistem baik perangkat keras maupun perangkat lunak dengan membentuk arsitektur sistem secara keseluruhan. Perancangan perangkat lunak melibatkan identifikasi dan penggambaran abstraksi sistem dasar perangkat lunak dan hubungannya.

\subsubsection{Implementation and Unit Testing}

Pada tahap ini, perancangan perangkat lunak direalisasikan sebagai serangkaian program atau unit program. Pengujian melibatkan verifikasi bahwa setiap unit memenuhi spesifikasinya.

\subsubsection{Integration and System Testing}

Unit-unit individu program atau program digabung dan diuji sebagai sebuah system lengkap untuk memastikan apakah sesuai dengan kebutuhan perangkat lunak atau tidak. Setelah pengujian, perangkat lunak dapat dikirimkan ke customer

\subsubsection{Operation and Maintenance}

Biasanya (walaupun tidak selalu), tahapan ini merupakan tahapan yang paling panjang. Sistem dipasang dan digunakan secara nyata. Maintenance melibatkan pembetulan kesalahan yang tidak ditemukan pada tahapan - tahapan sebelumnya, meningkatkan implementasi dari unit sistem, dan meningkatkan layanan system sebagai kebutuhan baru.(GinanjarWiroSasmito, 2017).

\subsection{Metode Prototype Untuk \\ Pengembangan Aplikasi Multimedia \\ Prototype merupakan salah satu} metode pengembangan perangat lunak yang banyak digunakan. Dengan metode prototyping ini pengembang dan pelanggan dapat saling berinteraksi selama proses pembuatan sistem. Prototyping, dimulai dengan pengumpulan kebutuhan pelanggan terhadap perangkat lunak yang akan dibuat, mendefinisikan objektif keseluruhan dari software, mengidentifikasikan segala kebutuhan, kemudian dilakukan "perangcangan kilat" yang difokuskan pada penyajian aspek yang diperlukan agar pelanggan lebih terbayang dengan apa yang sebenarnya diinginkan. Berikut adalah penjelasan untuk setiap fase Prototype:

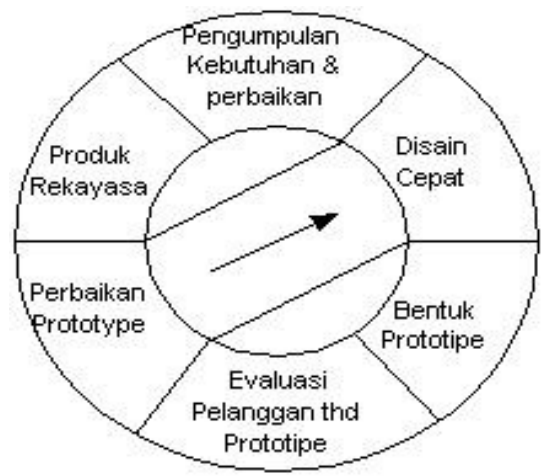

Gambar 2 Metode Prototype

\section{Hasil dan Pembahasan \\ 4.1 Analisis Sistem}

Sebelum melakukan perancangan sistem maka diperlukan analisis kebutuhan yang sesuai dan akurat. Untuk mendapatkan suatu data yang akurat, maka penulis perlu melakukan analisis kebutuhan sistem, analisis sistem yang sedang berjalan dan analisis sistem yang diusulkan.

Analisis kebutuhan Sistem Informasi Pemetaan Digital Kampus Muhammadiyah Riaudapat dijelaskan sebagai berikut :

\section{Kebutuhan Perangkat Keras (Hardware)}

Dalam pembuatanSistem Informasi Pemetaan Digital Kampus Muhammadiyah Riau Pekanbaru digunakan perangkat keras (Hardware) dengan optimal spesifikasi sebagai berikut :
1) Processor Intel Core i53GHz / AMD FX4100 3Ghz

2) Harddisk320GB (untuk sistem) 
3) Memory $8 G B D D R 3$

4) VGA dengan Memory $2 G B$

Untuk menjalakan aplikasi yang telah di compile maka membutuhkan minimum spesifikasi sebagai berikut :

1) Processor Intel Core i3 $2.7 \mathrm{GHz}$

2) Harddisk320GB (untuk sistem)

3) 20MB untuk aplikasi

4) Memory $2 G B D D R 3$

5) VGA Intel HD Graphic

6) Screenatau layar LCD/LED dengan fungsi speaker untuk notifikasi suara.

\section{Kebutuhan Perangkat Lunak (Software)}

Perangkat lunak (Software) yang digunakan dalampembuatanSistem Informasi Pemetaan Digital Kampus Muhammadiyah Riauadalah sebagai berikut :

1) Sistem Operasi Windows $7 / 10$

2) Adobe Edge Animate $C C$

3) Text Editor Sublime Text 2 (Optional)

\section{Kebutuhan Fitur Sistem}

Berdasarkan data yang didapatkan dari observasi, wawancara, dan studi literatur, maka diperoleh beberapa fitur sebagai berikut:

\begin{tabular}{|c|l|lr|}
\hline No & \multicolumn{1}{|c|}{ Kebutuhan } & \multicolumn{2}{|c|}{ Keterangan } \\
\hline 1 & $\begin{array}{l}\text { mengubah data dan } \\
\text { menambah } \\
\text { keterangan ruangan }\end{array}$ & $\begin{array}{l}\text { Menambah dan } \\
\text { mengubah data } \\
\text { ruangan } \\
\text { nama } \\
\text { keterangan detail } \\
\text { ruaungan. }\end{array}$ \\
\hline 2 & $\begin{array}{l}\text { Mencari ruangan } \\
\text { dengan menu yang } \\
\text { tersedia }\end{array}$ & $\begin{array}{l}\text { Dapat mencari } \\
\text { ruangan } \\
\text { berdasarkan tombol } \\
\text { menu yang telah } \\
\text { disediakan. }\end{array}$ \\
\hline 3 & $\begin{array}{l}\text { Menambah dan } \\
\text { mengubah keyword }\end{array}$ & $\begin{array}{l}\text { Menambah dan } \\
\text { mengubah data } \\
\text { keyword dalam } \\
\text { pencarian ruangan }\end{array}$ \\
\hline
\end{tabular}

\subsection{Perancangan Sistem}

Dalam pengerjaan suatu sistem, perancangan sistem berperan cukup penting, karena pada tahapan ini perancanaan seperti diagram dan design user interface dapat mempermudah pengerjaan sebelum masuk ke tahapan implementasi sistem.

\subsubsection{Perancangan Interface \\ Perancangan output merupakan} perancanganuntuk menghasilkan tampilan laporan-laporan yang diinginkan dari sistem. Berikut ini adalah perancanganoutput dari Sistem Informasi Pemetaan Digital Kampus Muhammadiyah Riau.

a. Perancangan Tampilan

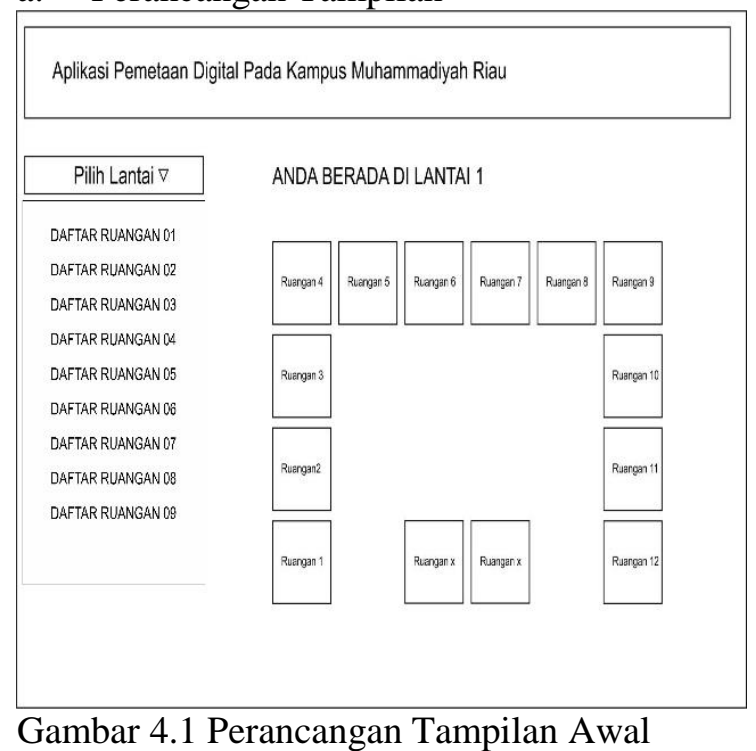
b. PerancanganLaporan Pilihan Lantai Gedung

Aplikasi Pemetaan Digital Pada Kampus Muhammadiyah Riau

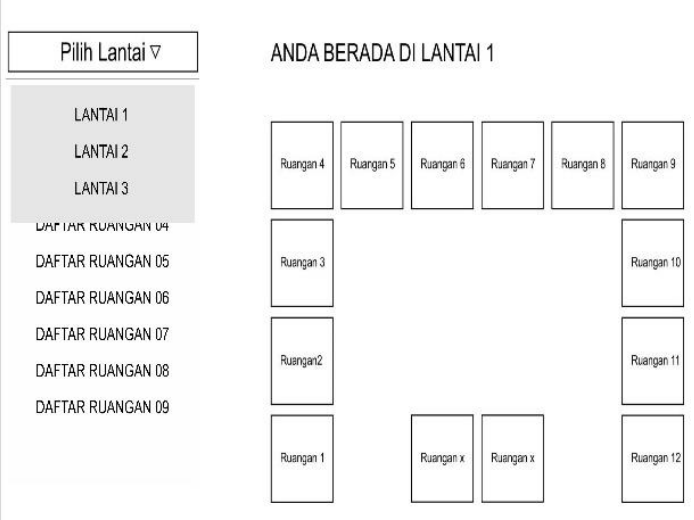

Gambar 4.2 perancangan Tampilan Pemilihan Lantai Gedung 


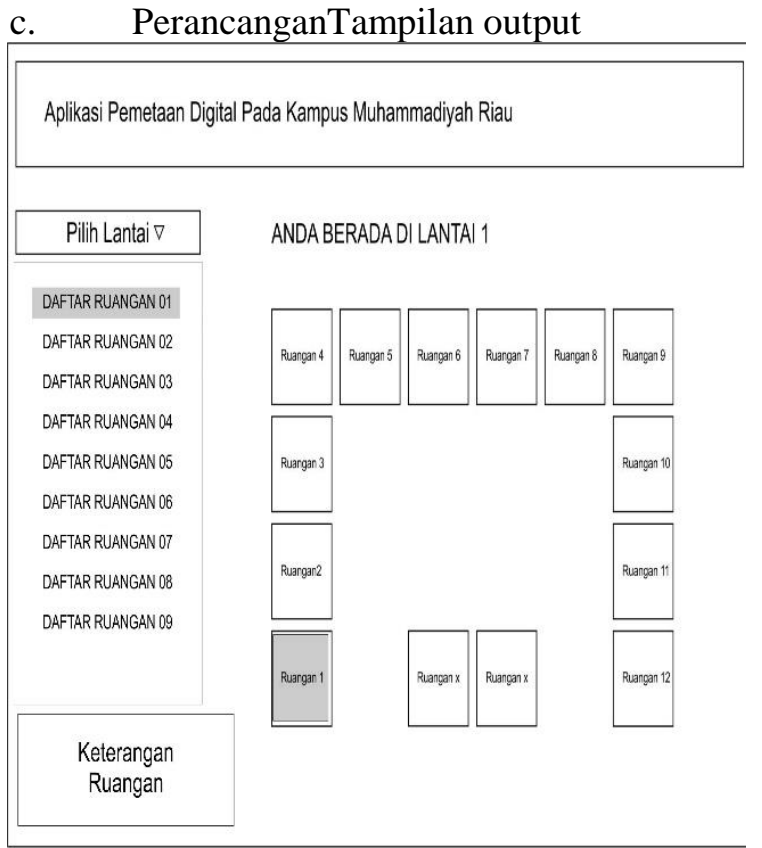

Gambar 4.3Perancangan Tampilan Input

\subsection{Perancangan Timeline Aplikasi}

Tahap perancangan timeline aplikasi merupakan penyusunan tahapan-tahapan sistem aplikasi. Karena berbasis flash, tampilan-tampilan yang ada pada aplikasi disusun berdasarkan timeline yang disediakan pada aplikasi Adobe Edge Animation yang nanti akan diprogram dengan Action script 3.0.

\subsubsection{Susunan Layer Object}

Layer Object merupakan tempat meletakan berbagai object yang dibutuhkan aplikasi. Berikut ini adalah tampilan menu Layerdari sistem informasi Pemetaan Digital Pada Kampus Muhammadiyah Riau.Tampilan menu Layer dapat dilihat pada Gambar 4.4

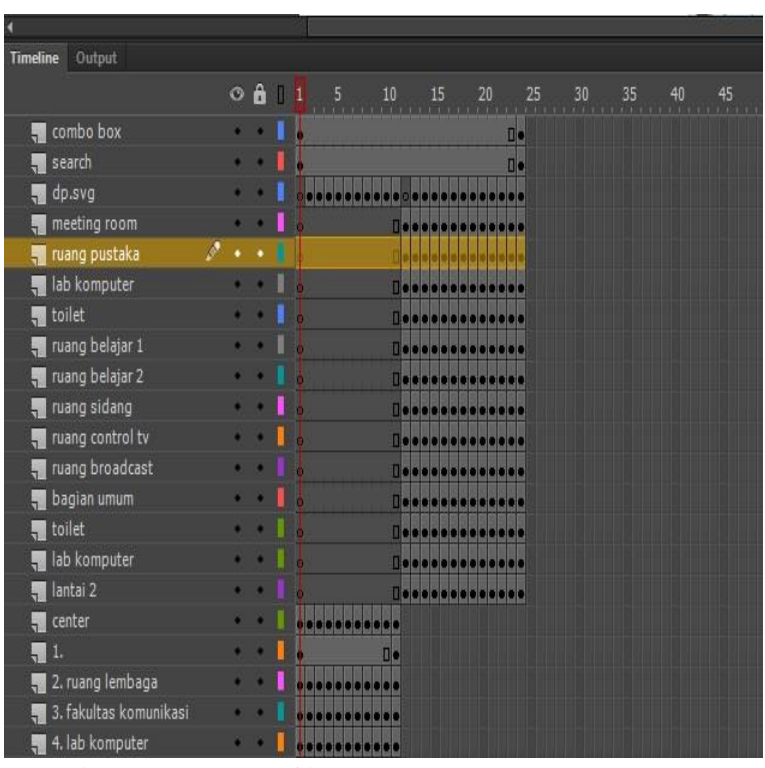

Gambar 4.4. Tampilan menu Layer

\subsubsection{Susunan Frame Object}

Frame Object adalah dimana objectobject yang sudah disusun sedemikian rupa pada layer, akan disusun kembali pada menu frame yang nantinya akan diprogram dengan action script 3.0. Berikut ini adalah tampilan menu Framedari sistem informasi Pemetaan Digital Pada Kampus Muhammadiyah Riau.Tampilan data dapat dilihat pada Gambar 4.5.

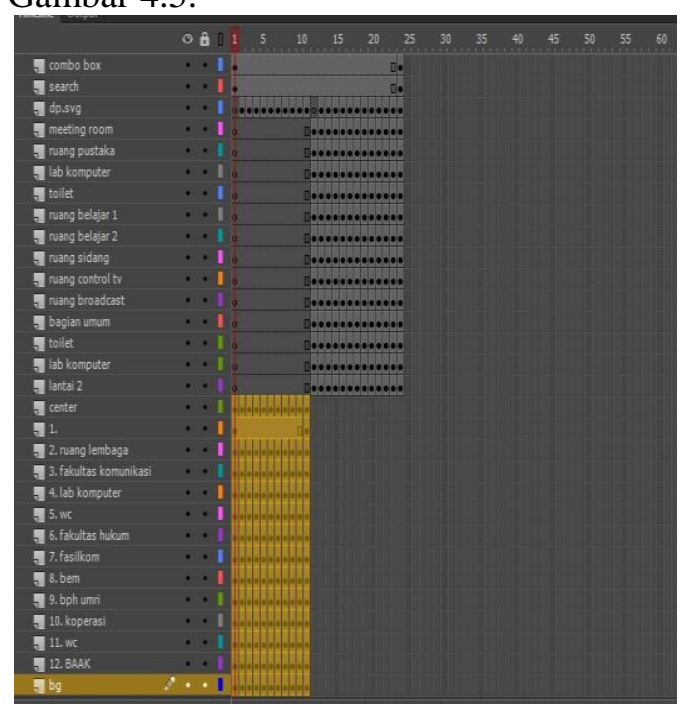

Gambar 4.5 Susunan Frame Object

\subsection{Action Script}

Tahap ini adalah untuk memberikan script ke object yang dibutuhkan agar aplikasi dapat berjalan.

\subsubsection{Script ComboBox} "pilih lantai"

Script ini ada untuk membuat menu combobox.addItem( I label:"pilih 
ISSN : 2550-0198

$$
\begin{aligned}
& \text { combobox.addItem( \{ label:"Lantai 1" } \\
& \text { \}); } \\
& \text { combobox.addItem( \{ label:"Lantai 2" } \\
& \text { \}); } \\
& \text { combobox.addItem( \{ label:"Lantai 3" } \\
& \text { \}); } \\
& \text { combobox.addEventListener } \\
& \text { if ( combobox.selectedItem.label }== \\
& \text { gotoAndStop(1); } \\
& \text { if (combobox.selectedItem.label }==
\end{aligned}
$$

"Lantai 2") 1

$$
\begin{aligned}
& \text { gotoAndStop (13); } \\
& \text { if (combobox.selecteditem.label }==
\end{aligned}
$$

"Lantai 3") \{

gotoAndStop $(26) ;$
(7) Adobe Flash Player 17
File View Control Help

\section{PILIH LANTAI}

\begin{tabular}{|l|}
\hline pilih lantai \\
\hline pilih lantai \\
\hline Lantai 1 \\
\hline Lantai2 \\
\hline Lantai 3 \\
\hline
\end{tabular}

Gambar 4.6Tampilan menu combobox

\subsubsection{Script Go to And Play/stop}

Script ini digunakan untuk mengarahkan object ke frame tertentu

fakultas_komputer.addEventListene r(MouseEvent.CLICK,

fl_ClickToGoToAndStopAtFrame);

$$
\begin{aligned}
& \text { function } \\
& \text { fl_ClickToGoToAndStopA } \\
& \text { (event:MouseEvent):void } \\
& \text { \{ } \\
& \text { \} gotoAndStop(02); }
\end{aligned}
$$$$
\text { fl_ClickToGoToAndStopAtFrame }
$$

\subsection{Implementasi Sistem}

Tahap implementasi sistem merupakan tahap meletakkan sistem supaya siap untuk dioperasikan. Tahap ini termasuk juga kegiatan menulis kode program dan perlu dipersiapkan seluruh perlengkapan yang dibutuhkan yaitu aplikasi yang telah siap dioperasikan. Implementasi bertujuan menyelesaikan pemodelan sistem yang sudah dirancang sebelumnya dan menguji dari Desain sistem. Tampilan menu output merupakan tampilan dari output yang telah diproses oleh Aplikasi Pemetaan Digital Pada Kampus Muhammadiyah Riau dari data yang telah dimasukkan sebelumnya. Berikut ini adalah tampilan menu output dari Aplikasi Pemetaan Digital Pada Kampus Muhammadiyah Riau.

\section{Tampilan Awal}

Pada tampilan awal, merupakan tampilan sambutan aplikasi

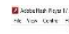

SELAMAT DATANG PADA APLIKAS PEMETAAN DIGITAL PADA UNIVERSITAS MUHAMMADIYAH RIAU KAMPUS 1

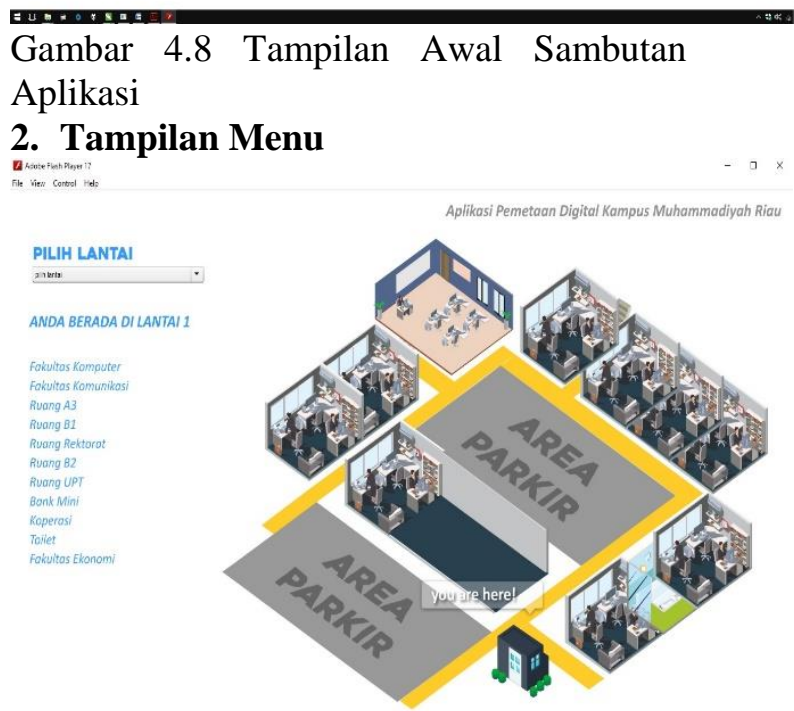

Gambar 4.9 Tampilan Menu Sistem

\subsection{Pengujian Sistem}

Pengujian sistem dimaksudkan untuk menguji semua elemen - elemen perangkat lunak yang dibuat apakah sudah sesuai dengan yang diharapkan. 


\section{Kesimpulan dan Saran}

\subsection{Kesimpulan}

Berdasarkan hasil penelitian pada tahap sebelumnya, maka penulis dapat memberi kesimpulan sebagai berikut :

1. Dengan adanya Sistem Informasi Pemetaan Digital Kampus Muhammadiyah Riau, dapat memberikan informasi yang aktual seputar ruangan dan fasilitas Kampus Muhammadiyah Riau.

2. Dengan adanya Sistem Informasi Poin Pemetaan Digital Kampus Muhammadiyah Riau, pemberitahuan mengenai keterangan ruangan menjadi lebih mudah dan praktis.

3. Dengan adanya Sistem Informasi Pemetaan Digital Kampus Muhammadiyah Riau, kesalahan dalam mencari informasi ruangan di Kampus Muhammadiyah Riau dapat diminimalisir.

\subsection{Saran}

Mengingat dalam penelitian ini masih memiliki banyak kekurangan, penulis menyarankan beberapa hal untuk pengembangan sistem informasi Pemetaan Digital Kampus Muhammadiyah Riau ke depan, antara lain:

1. Penambahan fitur yang lebih beragam agar diperoleh sistem informasi Pemetaan Digital Kampus Muhammadiyah Riau yang lebih baik.

2. Perbaikan tampilan agar Sistem Informasi Pemetaan Digital Kampus Muhammadiyah Riau dapat memberikan kenyamanan dalam memberikan informasi.

3. Pengembangan Aplikasi Pemetaan Digital Universitas Muhammadiyah Riau ke perangkat Android, maupun yang lainnya.

4. Penambahan kemampuan backup basis data secara otomatis untuk mencegah hal yang tidak diinginkan.

5. Pengembangan aplikasi penjadwalan otomatis ujian proposal dan sidang skripsi ke perangkat Android, maupun yang lainnya.

\section{DAFTAR PUSTAKA}

[1]. Astari, Tri Eko Addi. (2013), Media Informasi Berbasis Multimedia untuk Puskesmas Tambun, Yogyakarta.

[2]. Handono, Wahyu Tri, (2012), Perancangan Media Informasi Berbasis Multimedia pada Dinas Pariwisata Kabupaten Tuban, Yogyakarta.

[3]. Mubarok, Farid. Harliana, Ijah Hadijah (2015), Perbandingan Antara Metode RUP dan Prototype, Cirebon.

[4]. Rozi Pahrul, (2012), Perancangan Aplikasi Berbasis Multimedia Interaktif Sebagai Media Informasi Dan Promosi Pariwisata Danau Kerinci Di Kabupaten Kerinci, Yogyakarta

[5]. Sasmito, Ginanjar Wiro. (2017), Penerapan Metode Waterfall Pada Desain, Tegal.

[6]. Wibowo, Nur Cahyo, (2011), Analisis Dan Perancangan Media Informasi Registrasi Akademik Berbasis Multimedia Flash Di Kampus Upn "Veteran" Jatim, Surabaya.

[7]. Wijaya, David. (2015), Perancangan Media Informasi Berbasis Flash Pada Stmik Time, Medan 